\title{
Awareness and Acceptability of Ultrasound Prenatal Sex Determination among Pregnant Women in a Teaching Hospital in Sokoto, North- Western Nigeria
}

\author{
Yakubu Ahmed $^{1 *}$, Abubakar A. Panti ${ }^{1}$, Amina G. Umar ${ }^{1}$, Fatima A. Birnin-Yauri ${ }^{2}$, Jamila A. Garbar ${ }^{2}$, Rukayya Ibrahim ${ }^{2}$ \\ ${ }^{1}$ Department of Obstetrics and Gynaecology, Usmanu Danfodiyo University, Sokoto, Nigeria \\ ${ }^{2}$ Department of Obstetrics and Gynaecology, Usmanu Danfodiyo University Teaching Hospital, Sokoto, Nigeria
}

DOI: $10.36348 /$ sijog.2020.v03i04.001

| Received: 12.03.2020 | Accepted: 24.03.2020 | Published: 05.04.2020

*Corresponding author: Dr. Yakubu Ahmed

\section{Abstract}

Background: Improvement in ultrasonography over the years have allowed visualization characterization of fetal morphology. Objective: The study was aimed at determining the awareness and acceptability of ultrasound gender determination among women attending the antenatal care clinic of the Usmanu Danfodiyo university teaching hospital Sokoto. Materials and Methods: This study was a cross sectional study where pregnant women were selected by simple random sampling. The data was collected using pretested interviewer administered questionnaire. Relevant information was obtained. A P value $<0.005$ was considered statistically significant. Results: Among the 200 women recruited, (57\%) were within the age group of 20-29 years with a mean age of $28.2 \pm 5.436$. They were mostly (52.5\%) housewives and the Hausa/Fulani ethnic group constituted the majority 141(70.5\%). They were mainly, 161(80.5\%) Muslims and mostly, 92(46.0\%) had tertiary education. About half, $101(50.5 \%)$ belonged to social class 3 and $76(38.0 \%)$ were multiparae. About $84(42.0 \%)$ of them had no female children and 75 (37.5\%) had no male children. Majority, $159(79.5 \%)$ were aware that pre-natal gender determination can be assessed using ultrasound. Among them, 130 (65\%) were willing to know the babies' gender. There was statistically significant association between awareness of prenatal ultrasound gender determination and social class of the respondents $(\mathrm{P}=0.001)$. Among them, $55(43.3 \%)$ needed it to prepare for delivery. Conclusion: Awareness and acceptance of ultrasound gender determination is high among the study population. Acceptability depend on the clients' social class.

Keywords: Awareness, acceptability, prenatal, ultrasound, sex- determination.

Copyright @ 2020: This is an open-access article distributed under the terms of the Creative Commons Attribution license which permits unrestricted use, distribution, and reproduction in any medium for non-commercial use (NonCommercial, or CC-BY-NC) provided the original author and source are credited.

\section{INTRODUCTION}

Ultrasonography is part of the routine antenatal investigations usually done mainly for confirmation of viability of pregnancy and gestational age, identification of multiple pregnancy, localization of placenta, screening for fetal anomalies and general fetal wellbeing. This plays an important role in improving the antenatal care and outcome of pregnancy worldwide. Ultrasound is non-invasive, safe and less expensive with real time imaging capabilities that gives parents the image of the fetus [1].

Improvements in ultrasound have over the years allowed viewing the fetal morphology more clearly, and to detect fetal sex as, especially for increasing embryo size, and for male fetuses with accuracy between $70-90 \%$ in the first trimester $[1,2]$ and between $99-100 \%$ in the second trimester [3]. Prenatal gender determination is performed for medical and social reasons. Medical reasons for prenatal gender disclosure include X-linked disorders, ambiguous genitalia, testicular feminization syndrome, and assignment of zygosity in twin pregnancy. Although it is considered ethically unjustified if done for non medical reason, however, but has continued to grow in demand due to pregnant womens' requests [8]. This practice is tolerated because there is no evidence or scientifically proven harm to the fetus. Worldwide studies have shown that majority of women desire to know the gender of their fetus [5-12]. Majority of these studies have shown preference for male children over 
female children $[6,7,9,12]$. While a study from Poland showed no specific gender preference [11].

This has resulted in strong gender discrimination in towns and tribes in relation to food and education [10, 12 14, 18 19]. In some countries, there are strict laws barring gender disclosure to combat gender selection and feticide [12, 13]. However, gender disclosure is regarded as a human rights issue that should not be denied upon request in some countries9. In Nigeria, there are no laws guiding prenatal gender [5-11].

Despite the widespread awareness of prenatal sex determination worldwide some women may still be unaware. Among those aware, some for one reason or the other may not consider it acceptable. Previous studies in, Enugu and Ibadan [9, 15], Nigeria have shown that majority of women are aware of ultrasound gender determination and desire to know the gender of their babies through ultrasound. Similar findings were reported from Uganda [8], Pakistan [19], Nepal [20] and China [18]. However no such Study was reported from our. Therefore, the need to access the awareness and acceptability of ultrasound gender determination, acceptability and associated factors.

\section{MATERIALS AND METHOD}

It was a cross-sectional study that involved 200 women who presented at the booking clinic of the Usmanu Danfodiyo University Teaching Hospital Sokoto. They were selected using simple random sampling method by balloting following informed consent.

Data was collected using a pre-tested interviewer administered questionnaire. The information obtained include; sociodemographic characteristics, awareness about pre-natal ultrasound sex determination and acceptability of prenatal ultrasound sex determination. The social class of the respondents was determined using modified Oyedeji's method [24] Socio economic index scores were awarded to the respondents based on their level of education, their occupation and the occupation of their husbands. The mean of those scores was assigned as the social class

Data obtained was managed using Statistical Package of Social Sciences (SPSS) version 16.0.

Association between awareness and social class was assessed using chi square test. Level of significance was set at $\mathrm{P}<0.05$. The results were presented in text, tables and charts.

\section{RESULTS}

Of the 200 women recruited, their ages ranged between $18-39$ years and the modal age of 20-29 years, $68(56.7 \%)$ with a mean of $28.2 \pm 5.436$ years.

Majority of the respondents, 105 (52.5\%) were housewives. The Hausa/Fulani ethnic group were the majority, 141(70.5\%), and mostly, 161(80.5\%) practice Islamic religion. Those with tertiary level of education comprised $92(46.0 \%)$ and about $101(50.5 \%)$ belong to social class 3 and $(70.5 \%)$ were in monogamous family setting. They were mostly multiparous women that constituted $76(38.0 \%)$. Among them, $84(42.0 \%)$ had no male child and $75(37.5 \%)$ had no female child. Table-1 shows the socio-demographic characteristics of the respondent.

Table-1: Sociodemographic characteristic of the

\begin{tabular}{|c|c|c|}
\hline \multicolumn{3}{|c|}{ respondents } \\
\hline Variable & Frequency & Percentage \\
\hline $\begin{array}{l}\text { Age (years) } \\
11-19 \\
20-29 \\
30-39\end{array}$ & $\begin{array}{l}10 \\
114 \\
76\end{array}$ & $\begin{array}{l}5.0 \\
57 \\
38\end{array}$ \\
\hline $\begin{array}{l}\text { Social class } \\
\text { i } \\
\text { ii } \\
\text { iii } \\
\text { iv } \\
\text { V }\end{array}$ & $\begin{array}{l}82 \\
61 \\
25 \\
20 \\
25\end{array}$ & $\begin{array}{l}41 \\
30.5 \\
12.5 \\
10 \\
6.0\end{array}$ \\
\hline $\begin{array}{l}\text { Parity } \\
1 \\
2-4 \\
5 \\
>5\end{array}$ & $\begin{array}{l}36 \\
62 \\
76 \\
26\end{array}$ & $\begin{array}{l}18 \\
31 \\
38 \\
13\end{array}$ \\
\hline $\begin{array}{l}\text { Family setting } \\
\text { Monogamous } \\
\text { Polygamous }\end{array}$ & $\begin{array}{l}141 \\
59\end{array}$ & $\begin{array}{l}70.5 \\
29.5\end{array}$ \\
\hline $\begin{array}{l}\text { Religion } \\
\text { Islam } \\
\text { Christianity }\end{array}$ & $\begin{array}{l}161 \\
39\end{array}$ & $\begin{array}{l}80.5 \\
19.5\end{array}$ \\
\hline Total & 200 & 100 \\
\hline
\end{tabular}

Majority, $159(79.5 \%)$ are aware that prenatal gender determination can be performed by ultrasound, and only 41 (20.5\%) were not aware. Figure-1 describe the awareness of the respondents on ultrasound gender determination. 




Fig-1: Awareness of ultrasound gender determination

The main source of information is the doctor for $88(44.0 \%)$ While, Significant proportion 55
(27.5\%), also heard from friends. Details is as shown on Figure-2 below.

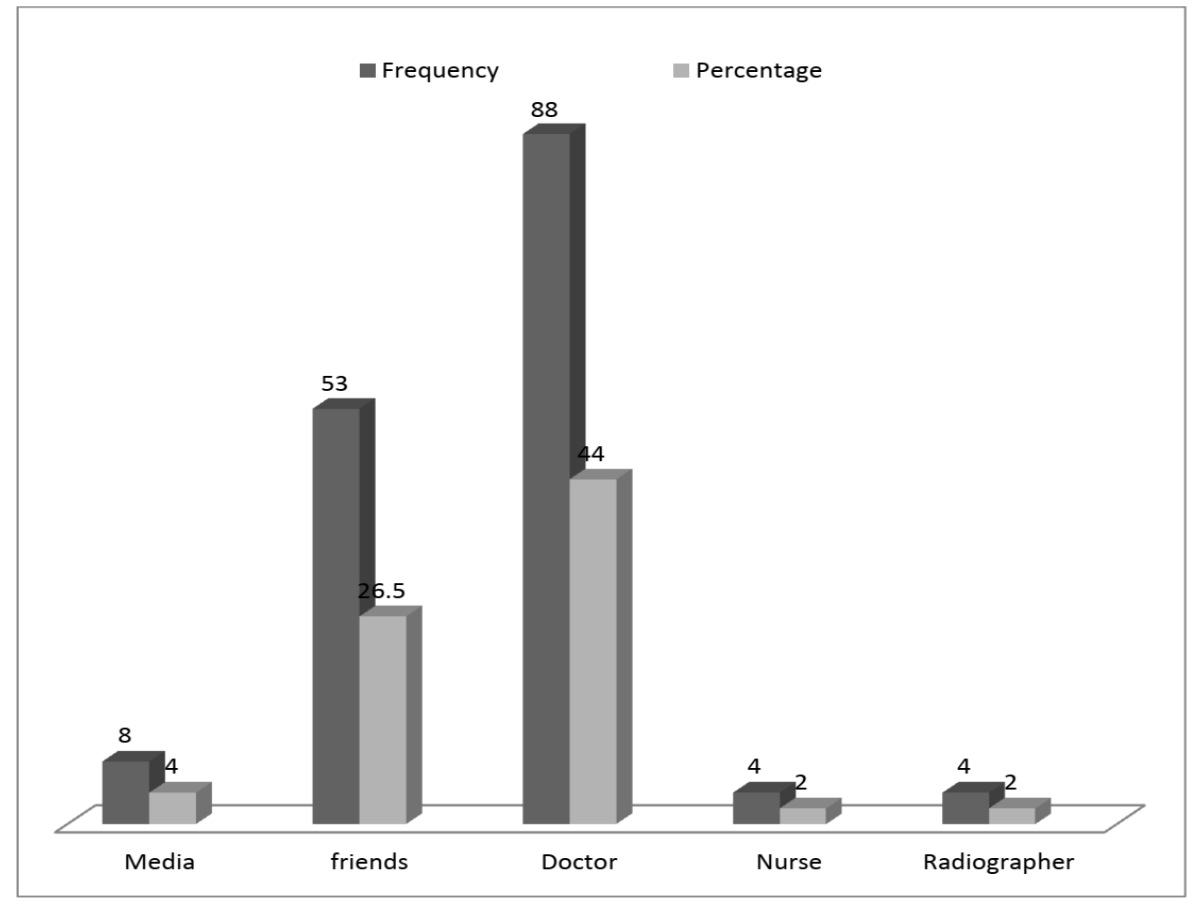

Fig-2: Source of information on ultrasound gender determination

Majority of the respondents $130(65 \%)$ will accept ultrasound gender determination if offered, while 70(35\%) will not. Among them, 55 (43.3\%) will accept in order to make preparation for delivery, While, 46 $(35.6 \%)$ were just curious to know everything about their babies. Others, $29(22.3 \%)$ want to confirm the accuracy of the ultrasound.
As for those that declined, $52(74.3 \%)$ don't want to raise anxiety, $4(5.7 \%)$ believed it is against their culture, while $12(17.1 \%)$ said it is against their religion. Figure-3 summerized the reasons of the respondents for not accepting ultrasound gender determination. 


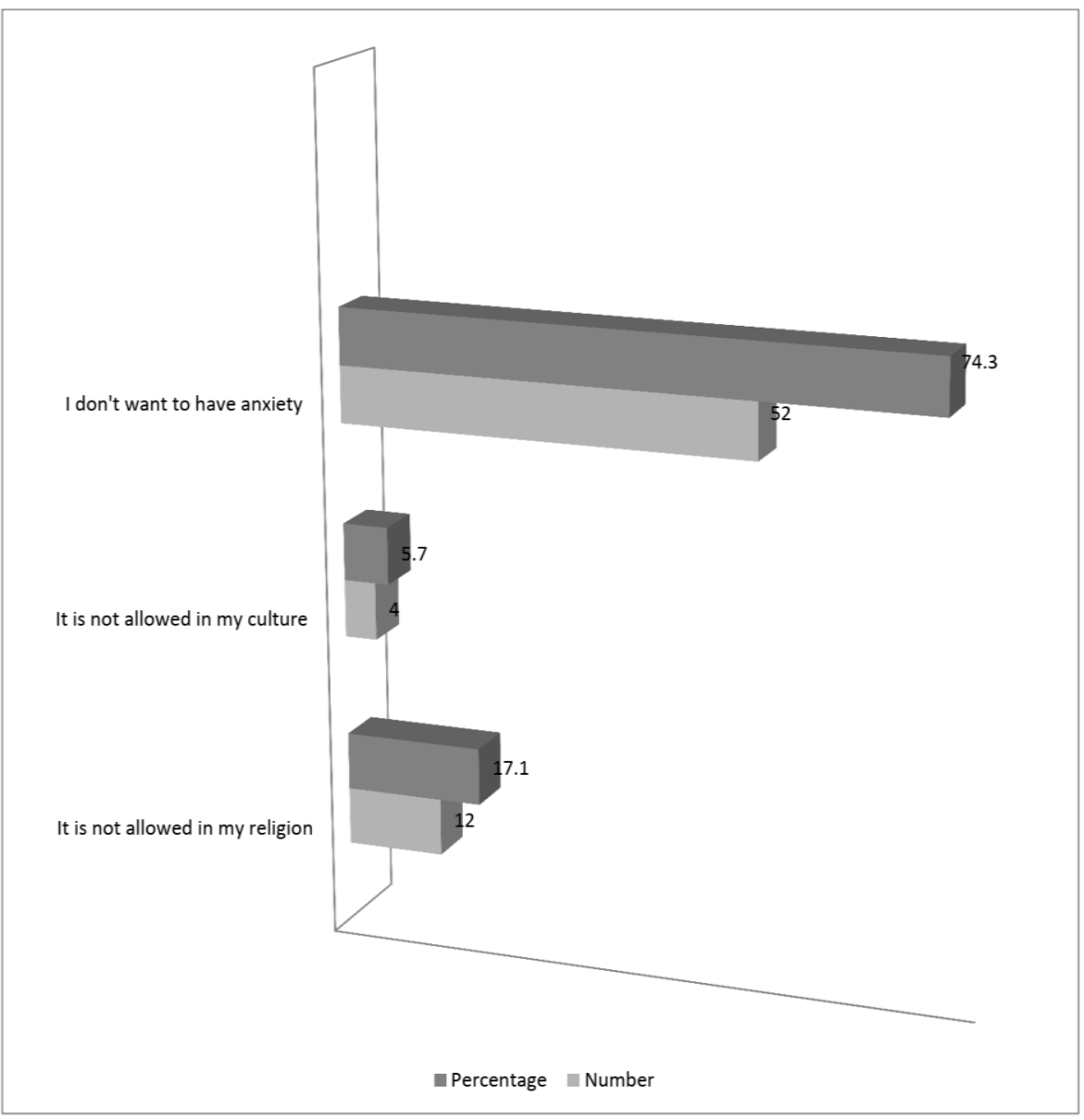

Fig-3: Reasons for not accepting ultrasound gender determination

There is statistically significant association between social class and awareness of ultrasound gender determination as there is increase awareness with increasing social class at P-value of 0.000 . It is also evident that more than $80 \% 11 / 12$ of those at social class $\mathrm{V}$ were not aware of ultrasound gender determination.

However, there is no statistically significant association between the social class of the respondents and their acceptance of ultrasound gender determination at p- value of 0.084 . As majority $(75 \%)$ in the lower social class were willing to have prenatal ultrasound gender determination.

\section{DISCUSSION}

This study shows that $79 \%$ are aware of ultrasound gender determination. The finding is in conformity with that reported from south India (87.5\%) [24] and Enugu Nigeria (90\%) [9]. However it is much higher than what was found from two community based studies from Karnaka ${ }^{6}$ and West Bengal [7] India that found only $4.5 \%$ and $44.5 \%$ awareness among women of reproductive age group. These differences are likely due to larger sample size and ours is an institution based study with smaller sample size [24].
In this study, the main source of information regarding prenatal ultrasound gender determination was from the doctors in $88(44 \%)$. This differ from the Indian study were majority $66.41 \%$ [24] got their information from the media. This is not surprising because in Nigeria, there is no law restricting prenatal gender determination. Therefore, health workers can freely discuss the issue without the fear of being punished by the law. While in India ${ }^{22}$ and countries like China ${ }^{23}$ there are laws and advocacy for laws restricting prenatal gender determination in order to halt the menace of selective fetocide in favor of the male gender.

Acceptability of ultrasound gender determination is also high in this study at $65 \%$. However, it is lower than $90 \%$ reported from Enugu, Nigeria. It is also lower, $91.2 \%$ than that was found among polish women [11]. This is probably because the respondents in the previous studies were those who had already discussed the issue of gender determination with their doctors before presenting for ultrasound.

The reason for accepting ultrasound prenatal gender determination is mainly to make preparation for the arrival of the baby, 55(43.2\%). This is comparable to the finding in Enugu of $52.4 \%$ and the Polish women $77.6 \%$ [11]. This however, to what is obtained in China 
and some other Asian countries where theirs is mainly for selective female fetocide [16-22]. For those who declined gender determination, their main reason was that they did not want to have anxiety over the possibility of the ultrasound finding turning out to be wrong. This differ from the finding in previous studies in Enugu where majority of the respondents just prefer to know the sex of their baby after delivery and prefer to leave everything to the will of God [9].

\section{CONCLUSION}

Awareness and acceptability of ultrasound prenatal gender determination is high among women who come for antenatal care visit in our center. Social class significantly affects the women's knowledge on ultrasound gender determination.

Acknowledgement: We acknowledge the Hospital management that gave permission and the patients who consented to participate and made the study a success.

\section{Conflict of interest: None.}

\section{REFERRENCES}

1. Savirón-Cornudella, R., González-Ballano, I., Cisneros-Gimeno, A., Lerma-Puertas, D., PérezPérez, P., Montañés-Bello, P., \& de León-Luis, J. (2015). Ultrasound measurement learning of fetal sex during the first trimester: does the experience matter?.Research and Reports in Focused Ultrasound, 3, 19-23.

2. Kong, C. W., Tong, L. Y., Lam, W. C., Chan, L. W., \& To, W. W. K. (2016). Learning curve in determining fetal sex by first trimester ultrasound scan. Journal of Medical Ultrasound, 24(2), 5459.

3. Odeh, M., Grinin, V., Kais, M., Ophir, E., \& Bornstein, J. (2009). Sonographic fetal sex determination. Obstetrical \& gynecological survey, 64(1), 50-57.

4. Leung, J. L. Y., \& Pang, S. M. C. (2009). Ethical analysis of non-medical fetal ultrasound. Nursing ethics, 16(5), 637-646.

5. Srivastava, A., Singh, J. V., Singh, O. P., Singh, V. K., \& Singh, N. (2014). Gender preference, attitude and awareness of young eligible couples towards pre natal sex determination in Lucknow district. Community Med, 5(1), 148-152.

6. Kulkarni, R. R., Bandireddy, M., \& Reddy, N. S. B. (2016). A community based cross sectional study on gender preference, awareness and attitude regarding sex determination among married women in rural field practice areas of North Karnataka, India. International Journal of Community Medicine and Public Health,3(11), 2973-2976.

7. Roy, A., \& Biswas, R. (2017). A study on gender preference and awareness regarding prenatal sex determination among antenatal women in a rural area of Darjeeling district, West Bengal, India. Journal of clinical and diagnostic research: JCDR, 11(2), LC05.

8. Gonzaga, M. A. (2011). An exploratory study of the views of Ugandan women and health practitioners on the use of sonography to establish fetal sex. Pan African Medical Journal, 9(1):3.

9. Okeke, T. C., Enwereji, J. O., Okoro, O. S., Iferikigwe, E. S., Ikeako, L. C., Ezenyeaku, C. C., \& Adiri, C. O. (2015). Desire for prenatal gender disclosure among primigravidae in Enugu, Nigeria. Patient preference and adherence, 9, 429. 433.

10. Westley, S. B., \& Choe, M. K. (2007). How does son preference affect populations in Asia? Hawaii: Analysis from East-West Centre.

11. Robak-Chołubek, D., Chołubek, G., \& Piróg, E. (2015). Determining fetal sex in pregnancy with reference to pregnant women behavior in late pregnancy. Polish Journal of Public Health, 125(2), 87-89.

12. Kishwar, M. (1995). When daughters are unwanted sex determination tests in India. Manushi. 86:15-22.

13. Edwards, H., \& Thomson, N. (2012). Social and practical implications of fetal sex determination using ultrasound. Ultrasound, 20(1), 49-53.

14. Kale, R. (2012). "It'sa girl!" — could be a death sentence. CMAJ. 184:387-388.

15. Enakpene, C. A., Morhason-Bello, I. O., Marinho, A. O., Adedokun, B. O., Kalejaiye, A. O., Sogo, K., ... \& Enabor, O. O. (2009). Clients' reasons for prenatal ultrasonography in Ibadan, South West of Nigeria. BMC women's health, 9(1), 12.

16. Kumar, N., Darshan, B. B., Bhaskaran Unnikrishnan, T. K., Thapar, R., Mithra, P., Kulkarni, V., \& Holla, R. (2014). Awareness and attitudes regarding prenatal sex determination, pre-conception and pre-natal diagnostic techniques act (PCPNDTA) among pregnant women in Southern India. Journal of clinical and diagnostic research: JCDR, 8(10), JC09.

17. Zhou, C., Wang, X. L., Zhou, X. D., \& Hesketh, T. (2012). Son preference and sex-selective abortion in China: informing policy options. International journal of public health, 57(3), 459-465.

18. Qadir, F., Khan, M. M., Medhin, G., \& Prince, M. (2011). Male gender preference, female gender disadvantage as risk factors for psychological morbidity in Pakistani women of childbearing agea life course perspective. BMC public health, 11(1), 745.

19. Chhetri, U. D., Ansari, I., Bhandary, S., \& Adhikari, N. (2011). Sex preferences among mothers delivering at Patan Hospital. Kathmandu University Medical Journal, 9(4), 229-232.

20. National Population Census 2006. (2007). Federal Republic of Nigeria. Gazette. 94:24-196. 
21. Bhaktwani, A. (2012). The PC-PNDT act in a nutshell. The Indian journal of radiology \& imaging, 22(2), 133-134.

22. Nie, J. B. (2011). Non-medical sex-selective abortion in China: ethical and public policy issues in the context of 40 million missing females. British medical bulletin, 98(1), 7-20.

23. Sharmila, V., Babu, T. A., \& Singh, D. (2016). Knowledge, awareness and attitude about prenatal sex determination, pre-conception and pre-natal diagnostic techniques act among pregnant women in the South Indian union territory of Puducherry. International Journal of Reproduction, Contraception, Obstetrics and Gynecology, 5(10), 3470-4.

24. Oyedeji, G. A., Oyedeji, A. O., \& Ajibola, A. J. (2002). The association between social disadvantage and morbidity in hospitalised children. Nigerian Journal of Paediatrics, 29(1), 5-10. 